\title{
La oposición en la transición política peruana entre los años 2000 y 2002
}

\author{
Gustavo Hermoza Alarcón \\ Universidad Nacional Mayor de San Marcos \\ < ghermoza0@gmail.com >
}

\section{RESUMEN}

El tema a investigar es cómo fue la participación de los partidos políticos durante el fin del fujimorismo. La constitución de las agrupaciones, quiénes eran líderes y qué ideas predicaban. También su relación con sus electores, cuáles eran sus debilidades y fortalezas. En primer lugar, la partidocracia que surge a comienzos del siglo xxI, se caracteriza por ser una estructura sin bases institucionales, cuyos líderes surgen de la total improvisación que ha dado paso el derrumbe del sistema de partidos de los ochenta. También surge un poder fáctico que desplaza al antiguo poder real que era el Ejército. Ese es la tecnocracia que se vuelve el mayor referente institucional. Asimismo, las ideologías políticas quedan de lado en estos nuevos tiempos.

Palabras clave: partidos políticos; transición democrática; democracia frágil; recuperación de la democracia.

\section{The Opposition in Peruvian Political Transition between years 2000 and 2002}

\begin{abstract}
The present research's topic is how was the political parties's participation during the end of Fujimorismo. It is specially analyzed partie's constitution, identifying leaders and their political ideology. Another relevant section of the research is about the relations with their social bases, explaining their weaknesses and strenghts in dealing with this issue. First, parties that emerged after 2000 are characterized by an structure lacking of institucional bases. Their leaders arises from improvisation, as a result of the party system collapse in the eighties. It is also remarked the influence of the Peruvian Army in local politics. In this context, technocracy becomes the most important institucional reference, aside with new political ideologies that compete in the electoral arena
\end{abstract}

KEYwORDs: politics parties; democratic transition; weak democracy; recovery of democracy. 


\section{Contexto mundial}

$\square_{\text {g }}^{\mathrm{g}}$

n este capítulo, se hablará sobre la oposición política que encabezo las marchas antigubernamentales. ¿Quiénes la conformaban? ¿Tenían proyectos de índole institucional? ¿Era una muestra de un renacimiento de los partidos ideologizados o una continuación de «los independientes» sin ideologías? Todas estas preguntas son importantes para comprender a los protagonistas de las marchas contra el régimen fujimorista. Se debe profundizar estos conceptos de esta parte de la historia. A pesar del clima de optimismo generado por la caída repentina del régimen fujimontesinista, ocultaba un hecho grave que afectó la legitimidad democrática en los años que siguieron al fin del Fujimorismo.

La manifestación de un sentido general que el contexto histórico que pertenece la oposición política y la posterior transición que esta fue protagonista, está marcado por la Tercera Ola de Democratización que data de comienzos de los ochenta. Cuando los regímenes dictatoriales pasaban a la historia mediante una pacífica transición, en la mayoría de los países. Esta etapa histórica coincide con la implementación de las políticas neoliberales en la economía. Por ello, todo el conglomerado de opositores políticos al fujimorismo se considera demócrata y apoya el neoliberalismo con rostro institucional sin el marcado autoritarismo del régimen que combatían. Pero la democratización de toda América Latina, incluyendo el Perú, estaba marcada por serias dificultades. Las repúblicas latinoamericanas se han caracterizado sus regímenes democráticos por una aguda ineficiencia, mantener terribles desigualdades sociales y una política marcada inestabilidad. La recuperación democrática peruana estaba sujeta a una temprana insatisfacción una vez que la euforia por la caída de la dictadura se hubiera desvanecido.

El siglo XX finalizaba, lo único que podía ofrecer la dinámica política eran los rostros de los caudillos que encabezaban los partidos independientes. Más que todo apenas podían diferenciarse del Fujimorismo en cuanto a discurso y métodos para ganarse a los votantes como apelación al clientelismo y populismo. Más aún con el asunto económico, donde estos no discutían el modelo neoliberal impuesto por el gobierno fujimorista. Los ciudadanos apenas vislumbraban diferencias entre los partidos de la oposición y el partido oficialista. Por ello, muy poca gente militaba en los partidos políticos cuan- do se dieron las movilizaciones contra el autoritarismo fujimorista al no estar representados.

La coyuntura electoral 2000-2001 no fue la excepción. Además el elector peruano, a fines del siglo $\mathrm{XX}$, se caracterizaba por su carencia de vínculos con organizaciones políticas. Dado que el sector informal que surgió tras las migraciones del campo a la ciudad y la crisis económica, disminuiría el peso de los sindicatos. En el pasado estas organizaciones tuvieron un importante peso en la política desde 1930 con la aparición del Apra y el Partido Comunista. Dado que podían mediar entre los trabajadores y la política. La ciudadanía peruana no era marcada por la polarización ideológica, como ocurrió en el pasado, más bien era favorable con las políticas que favorecían el libre mercado, por parte del régimen fujimorista; más no en que ese se perpetuase en el poder por tiempo indefinido.

\section{Situación de los Partidos Políticas}

La ciudadanía ganó y perdió a la vez ciertos elementos políticos para decir que está representada. En primer lugar recuperó las libertades políticas que estuvieron coartadas por las continuas reelecciones de Fujimori; pero por otra parte la vieja partidocracia que representaba los intereses de diversos sectores sociales (eje clase media, clase popular) se fue perdiendo y se cayó en la anomia institucional. Ya que la transición postfujimorato, valga la redundancia, no se funda fundamentó en un sólida partidocracia; sino en líderes mediáticos y personalistas, lo cual refleja la debilidad institucional como en el caso de Somos Perú, Solidaridad Nacional y Perú Posible que no pudieron consolidarse como partidos políticos institucionales.

En 1995 el Fujimorismo había cooptado a diversas figuras de los otroras partidos tradicionales especialmente del Apra y la antigua Izquierda Unida que formaron parte del engranaje partidario del Fujimorismo o en el mejor de los casos se identificaban como independientes para no perder vigencia en la arena electoral. Por ello se puede explicar que durante mucho tiempo, la oposición fue incapaz de ser una fuerza política consistente que pudiera hacer frente a las pretensiones de Fujimori de seguir perpetuándose en el poder. Muchas personas creyeron que el movimiento debilitaría al régimen fujimontesinista; mostrando cierta ingenuidad en su propósito. Ya que estaban 
centrados únicamente en quitar al Fujimorismo del poder. Es decir, ya no puede decirse que se construya poder real sobre la base de la movilización de sectores estratégicos como los trabajadores industriales y los estudiantes, como en la década de los ochenta.

El caso es que la política seguía estando dominada por partidos de marcado de personalismo en la arena electoral como el caso de Perú Posible. Parecía que un régimen autoritario personalista era remplazado por una democracia caudillista. Lo cual mostraba esa debilidad que ha tenido las transiciones democráticas en el Perú de los últimos tiempos. El periodo de 1978-1979, fue el que tuvo una mayor repercusión institucional, ya que un sistema de partidos con marcada identidad ideológica como PPC e Izquierda Unida. Pero a comienzos del siglo XXI, parecía que estaba resurgiendo el caudillismo. Era penoso asumir que la restauración democrática nacía frágil ante las circunstancias dadas. Por ello, la caída de la dictadura podía conducir a un falso triunfalismo que podía hacer olvidar esta terrible tara. Con el tiempo se demostró que el personalismo fue la marca preponderante de la política peruana en la década de los 2000. Los partidos no pudieron constituirse en organizaciones con propia autonomía... más bien la vigencia en el panorama político de los movimientos que participaron en los comicios de 2000 y 2001, estaban unidos inexorablemente a la figura de sus caudillos que le daba fuerza ante las masas.

Las organizaciones políticas opositoras, no tuvieron una permanente actividad opositora. Solo esta se daba en periodos electorales. Como podemos destacar, en el periodo 1995-2000 la oposición no tuvo un rol político que pudiera poner en guardia al régimen. El mejor ejemplo de ello es Perú Posible, cuando fue una organización inactiva que apenas era considerado por las masas. Totalmente dependiente de las decisiones que tome en la arena política. Se puede afirmar que todas las organizaciones políticas pasan por un periodo de hibernación, terminado los periodos electorales. Eso se da con fuerza a partir de la derrota que sufrió la oposición en 1995, con la segunda reelección fujimorista que los partidos políticos dejan de ser grandes referentes para la población. Al igual que el partido oficialista, su vida política comenzaba y terminaba en los comicios.

Los partidos políticos que estuvieron involucrados en las movilizaciones en contra de Fujimori, demostraban no ser lo suficientemente militantes para desarrollar un proyecto político que trascendiera el fin del Fujimorato. A diferencia del proceso político de 1978-1979 en que los partidos políticos tuvieron una notable participación hasta el punto de que estos lograron un aporte que culminó magistralmente con la promulgación de una nueva constitución. En cambio, en el transición política de 2000-2001, las agrupaciones políticas no tenían mayores prospectos... salvo ver fuera a Fujimori.

En los noventa, los partidos de Derecha les era muy difícil retornar al escenario nacional como había pasado con la candidatura de Lourdes Flores en que no pudo pasar la primera vuelta electoral. Las fuerzas políticas que estaban mejor consideradas como el Apra y Perú Posible mezclaban en sus planteamientos y propuestas la democracia social y el libre mercado, uno más que otro. El discurso popular estaba bastante presente en el electorado. Parecía que más que un discurso ideológico, era lograr captar a las masas con propuestas prácticas relacionados con la economía familiar de los ciudadanos que de por sí era precaria. El pueblo deseaba elegir a un mandatario que les solucionara el asunto económico, logrando que este lograra convencerlos con un discurso que enfatizara bastante el rol de los de abajo en la construcción de la democracia en el Perú

La Transición no generó mayores modificaciones sustanciales a la vida política, como el cambio de una nueva constitución o participar directamente en el gobierno. A diferencia del primer periodo en que los militantes y dirigentes que encabezaron la oposición contra la dictadura de Francisco Morales Bermúdez (especialmente los de izquierda) ocuparon cargos en el legislativo y participaron en diversas elecciones que dieron el triunfo a sus agrupaciones (ejm triunfo de Alfonso Barrantes en las municipales); los miembros de los colectivos de oposición se retiraron de la política apenas terminada la dictadura. Era muestra de que no estaba preparada para asumir tareas más complejas, como la de diseñar la política que seguía al fin del Fujimorismo

El debilitamiento de la partidocracia, es debido a la política que se ha adoptó tras el fin de la Guerra Fría. La reducción del aparato estatal ha hecho que los partidos políticos dejen de ser actores esenciales en esta dinámica. Podemos afirmar que en esta etapa de la historia, muchos de los protagonistas ya sean del oficialismo o de la oposición política no estaban interesados en tener una base partidaria importante. 
Más que todo está sumamente enfocado en la economía y generar un importante clima de negocios, en vez de fortalecer la democracia. A diferencia de otros periodos de la historia, en que las movilizaciones políticas estaban acompañadas por la expansión del Estado y fortalecimiento de la institución gubernamental. Ante este escenario, una partidocracia fuerte no puede gobernar en este escenario y se fomenta el discurso anti partido.

\section{Debilidad de los Partidos Políticos}

La debilidad de la partidocracia se debe más que nada al contexto que siguió a posteriori a la caída del Muro de Berlín, en que la lucha a muerte de los bloques ideológicos como el liberalismo capitalista como el comunismo eran parte de la historia. Entonces se puede inferir que la preminencia ideológica o una identidad partidaria fuerte no tenían lugar a fines del siglo XX. Además los estados nacionales dejaron de ser los importantes referentes para la ciudadanía de muchos países, en que predominó durante buena parte de la centuria pasado la consolidación del Estado-Nación a través de variantes políticas como el Comunismo, el Republicanismo y el Liberalismo. Ahora a comienzos del siglo XXI, el panorama era mucho más optimista porque la democracia estaba afianzándose en el continente luego de décadas de gobiernos dictatoriales. $\mathrm{E}$ inclusive en gobiernos autoritarios más recientes como los de Fujimori y Chávez se vieron obligados a tener que guardar las formas institucionales. Era increible lograr mayores resultados con los votos que con una violenta revolución o contrarrevolución golpista militar.

La mejor definición es: Protopartido, porque nunca desarrolló una estructura permanente después de los comicios donde salió triunfador su líder fundador. Además su militancia no tenía una sólida base partidaria como los tenía el Apra, AP y el PPC. Ya que esta se caracterizaba por identificarlo como una organización laxa, poco disciplinada en lo ideológico e interesada en satisfacer proyectos particulares más que institucionales. Además su norte estaba marcado por los avatares de su líder máximo, lo cual le quitaba margen de maniobra. Además su carácter heterogéneo hacía que no pudiera constituirse como un grupo serio, capaz de lograr mejores objetivos de constituirse como uno de los paladines partidarios de la democracia.
El peruposibilismo era lo mejor definición de lo que llamaríamos un protopartido o solamente un grupo coyuntural que aprovechaba para beneficiarse la situación de estar en el poder. Parecía que los partidarios de PPP no estaban acostumbrados a este tipo de contexto en que no estaban en campańa electoral, lo cual hizo que no pudieran adaptarse a ser un partido que fuera el soporte ideológico del gobierno, mas no un trampolín para obtener privilegios, puestos de trabajo o cargos ministeriales. Además consideraba que el presidente debía tener un enfoque más técnico, no distraerse en las cuestiones del partido. Su agrupación más que todo le estaba causando desprestigio a su figura, por ser considerado responsable de la baja aceptación de su gestión por parte de los ciudadanos.

Su base está en partidos y liderazgos débiles, que provocaron el vacío institucional de una década marcado por la antipolítica. La viabilidad para una nueva democracia fortalecida tras la transición es la renovación de ideas e instituciones políticas. Más que todo se debía lograr un importante legitimación de las conquistas ya ganadas, para evitar que se repitiera el catastrófico escenario político que fue el Perú a finales de los ochenta. Más allá que la transición debe destruir el orden imperante de un régimen autoritario se de reconstruir la institucionalidad democrática. Se ha salido del esquema de la antipolítica y más bien se ha enraizado con el pasar de los años.

En la época de la Guerra Fría los países en vías de desarrollo, estaban inmersos en dictaduras pendulares de izquierda y derecha (el totalitarismo maoísta de Pol Pot en Camboya y el régimen dictatorial del general Hugo Banzer en Bolivia de corte conservador). Habiendo muy poco espacio para la democracia, debido a la terrible carencia en materia estructural e institucional, inestabilidad política y paralizantes crisis económicas. Daba la impresión de que solamente en el mundo desarrollado e industrializado se podría hablar de un verdadero estado democrático. Pero con la caída del Comunismo, la democracia empezó a tener mayor margen de maniobra. Además vieron esto como una oportunidad para muchos países en vías de desarrollo de lograr acuerdos económicos, abandonado o suavizando el autoritarismo que había caracterizado su forma de gobernar. Por ello, las cuestiones ideológicas pasan a un segundo plano. Ya que la representatividad democrática en lo teórico es difícil de cuestionar.

En noviembre de 2000, al darse la súbita caída del Fujimorismo renació una cierta esperanza porque 
en nuestro país la política sería honrada y limpia a partir de este momento. Aunque se resalta mucho la diferencia clave de los movimientos de protestas del pasado, con los de comienzos de siglo. En primer lugar, el clamor tenía un carácter social, debido a la subida de los precios de los alimentos, la disminución del poder adquisitivo y la carestía. Por ello, los sindicatos y partidos de izquierda fueron los que tomaron la batuta e identificándose con las paralizaciones. Además en 1977, durante el gobierno de Morales Bermúdez, el Perú vivía en Estado de Emergencia y con las garantías constitucionales totalmente suspendidas. Pero en este contexto que investigamos, los reclamos de la población estaban dirigidos a un proceso electoral limpio, que no fuera una vergonzosa forma de legitimar una falsa democracia con la tercera reelección de Fujimori. El país no vivía un estado de emergencia ni se tomaron medidas de represalia de gran envergadura.

La ciudadanía creyó ilusionadamente que la caída de su autoritario régimen sería un nuevo amanecer para la historia del Perú, favorecido por la coyuntura de la llegada del nuevo siglo. Las razones que llevaron al fin de esta ilusión. La transición política no tuvo un carácter revolucionario, su objetivo no era cambiar la sociedad, como fue en el pasado; sino más bien cuestionar las irregularidades de las elecciones que daban por ganador a Fujimori. Por ello se puede explicar porque los gobiernos democráticos que salieron elegidos terminaron siendo impopulares y carentes de legitimidad. También de que esto fue un mero cambio cosmético y convirtiéndose todo esto en una falsedad. La herencia que dejó el Fujimorismo, se impusieron una lógica movimientista y populista que les imponían como límite. Además los candidatos, unos más que otros, no plantearon alternativas para el neoliberalismo, tampoco como se podía reconstruir la democracia una vez caído el Fujimorismo. Preferían arrinconarse al centro, por ser una opción adecuada. Tal situación fue resultado de un «acuerdo» implícito debido a que ninguno de ellos se sentía con la suficiente seguridad como para polarizar la competencia ni ser una fuerza hegemónica.

El fin del Fujimorismo en realidad no cambió un estilo de hacer política, más bien lo acrecentó aún más. Muchos de los parlamentarios fujimoristas retuvieron sus puestos en el congreso. Lo cual es el primer paso para desmitificar este periodo histórico y lograr plasmar una realidad histórica. La debilidad de los partidos se reflejó mucho en los parlamentarios que cambiaron a menudo de bancada y podemos descubrir que la transición política no ayudó a cimentar la posición del parlamento como el poder del Estado que había logrado cambiar su imagen deteriorada por la corrupción fujimorista

Los partidos políticos que estuvieron involucrados en las movilizaciones en contra de Fujimori, demostraban no ser lo suficientemente militantes para desarrollar un proyecto político que trascendiera el fin del Fujimorato. A diferencia del proceso político de 1978-1979 en que los partidos políticos tuvieron una notable participación hasta el punto de que estos lograron un aporte que culminó magistralmente con la promulgación de una nueva constitución. En cambio, en el transición política de 2000-2001, las agrupaciones políticas no tenían mayores prospectos... salvo ver fuera a Fujimori. No planteaban mayores cambios, como el cambio de una nueva constitución o participar directamente en el gobierno. A diferencia del primer periodo en que los militantes y dirigentes que encabezaron la oposición contra la dictadura de Francisco Morales Bermúdez (especialmente los de izquierda) ocuparon cargos en el legislativo y participaron en diversas elecciones que dieron el triunfo a sus agrupaciones (ejm triunfo de Alfonso Barrantes en las municipales); los miembros de los colectivos de oposición se retiraron de la política apenas terminada la dictadura. Era muestra de que no estaba preparada para asumir tareas más complejas, como la de diseñar la política que seguía al fin del fujimorismo.

Organismos que en la práctica más son una maquinaria ideológica que busca un fin específico (ejm elecciones). El esquema planteado por el autor era casi imposible de implementar, dado que el sistema de partidos endebles que carecían de un objetivo más allá de forzar la salida de Fujimori del poder. Tampoco e destacan por su aportes intelectuales en la historia peruana en cuanto a propaganda, doctrina, organización y cualidades de sus principales líderes en que se destacaban intelectuales comprometidos como Luis Alberto Sánchez, Magda Portal, Ciro Alegría, Antenor Orrego, César Vallejo, César Falcón y Alcides Spelucín que aportaron bastante a la identidad política. En cambio los partidos «independientes» se caracterizaban por la presencia de tecnócratas y economistas. Es un patrón que continúo tras la caída de Fujimori, al estar la política peruana dominada cada vez por líderes mediáticos que por políticos serios y careciendo de ideario que los diferenciaba unos de otros. 


\section{Características de los partidos políticos}

Las fuerzas opositoras solo coincidían en una agenda: Deshacerse del viejo régimen y restablecer la democracia. En que el movimiento popular estaba más enfocado en satisfacer demandas de satisfacer las ansias de justicia de un sector de la población que había sido afectado por la política económica del Fujimorismo. A pesar de la movilización, la oposición popular y no vinculada con los partidos políticos tuvo un rol marginal. En que organizaciones sociales, sindicatos como la CGTP y confederaciones campesinas no participarían en la transición a partir de ese entonces cuando cayó el régimen. Aquello no fue una repetición de las grandes movilizaciones de finales de los setenta en que los movimientos sociales tenían metas políticas más ambiciosas que estaban más allá de terminar el régimen militar y esto llevó a profundos cambios como una nueva constitución y mayores derechos civiles.

La oposición política no tomó en consideración los errores del pasado que había logrado capitalizar Fujimori para imponer su régimen autoritario a partir del autogolpe. Es por ello que culpar únicamente al régimen anterior; porque no se logró hacer que la transición política pudiera tener un cauce más institucional más que electorero. Es una muestra sobre la incapacidad de un verdadero mea culpa que logre articular una nueva clase política capaza de movilizar a las masas. Más que ello, se basa en la premisa simplista sobre el único responsable de que nuestra república no tenga una fuerte partidocracia ha sido el autoritarismo fujimorista.

El un enfoque económico tuvo una importante atención por parte de la nueva clase gobernante, lo cual ha generado una homologación que han hecho varias naciones al adoptar el esquema neoliberal en mayor o menor medida a partir de la década de los ochenta. Las diferencias nacionales habían quedado prácticamente suprimidas por la marcha de la economía. La fortaleza de un país estaba en adoptar los patrones económicos neoliberales que tener una partidocracia fuerte. Por ello, se puede explicar por el poco interés de los políticos en querer mejorar la situación de los partidos políticos como ejes de desarrollo institucional.

El carácter heterogéneo, le ha impedido mayor cohesión, articular planes y propuestas ciudadanas. El decenio fujimorista había convertido a la oposición política en un ente vegetativo, que solo adquiría importancia política en época de elecciones, si estos lograban estar liderados por un líder carismático que pudiera tener química con las masas, especialmente de los sectores populares. En ese tiempo, la partidocracia no pudo constituirse como una oposición tomada en serio por parte de la población, eso reflejaría sus pobres resultados en el campo electoral, si no estaban liderados por caudillos carismáticos. El retorno de la democracia, no pudo corregir el esquema de una presidencia que no estaba respaldada por una mayoría parlamentaria y hasta se volvía una cuestión casi normal.

El variopinto movimiento que encabezó la transición que siguió a Fujimori y que no tenía objetivos a largo plazo, llevada a cabo con improvisación, agudo personalismo por parte de los líderes de sus respectivos movimientos políticos que se enfrentaron al fujimorismo, enfocada en ganar las elecciones, sumamente debilitados para el momento y sin construir un proyecto político de por medio. Al igual que el fujimorismo, no propugnaba un proyecto nacional que pudiera marcar la diferencia y crear el camino para la reforma. La presencia de militantes del Peruposibilismo, solo agravó el problema al estar asociados a la corrupción y al nepotismo. Por ello la partidocracia quedó desprestigiada y considerada incapaz de asumir puestos en la administración pública. Ya que su experiencia solo estaba centrada en el ámbito electoral, más no en otros ámbitos como planes de gobierno de largo plazo.

Los partidos que encabezaron las marchas contra Fujimori, fueron de carácter capitalino, sin una estructura orgánica que pudiera aglutinar a las masas y apenas tuvieron lazos con otros grupos opositores provincianos que combatían al Fujimorismo. Más que todo no involucrar a los frentes regionales que protestaron contra el gobierno fujimorista en su organización política. Jamás se constituyeron partidos nacionales, los partidos de la oposición. Teniendo un carácter coyuntural y cuando terminó la dictadura los vínculos se rompieron, tras dos años transcurridos desde la caída del Fujimorismo no se habían logrado afianzarse como fuerza nacional.

La desunión fue una de las principales características de la oposición política, dado el enorme personalismo que los caracterizaban. Lo irónico era que los partidos tradicionales como el APRA, el PPC, AP y la Izquierda eran los elementos más débiles de la oposición; al contrario los partidos independientes cuyos líderes apenas tenían experiencia en la política fueron los que tuvieron mayor margen de maniobra 
política. Asimismo hubo mucha desconfianza entre las agrupaciones políticas, por el asunto relacionado quien de estas podía tener mayor arraigo en el electorado. El debilitamiento de los partidos tradicionales hacía que se acrecentara aquella desconfianza de ser tomado como un importante aliado político. Por ello, las reticencias de querer unirse ambos grupos que tenían un objetivo común; pero diferentes estrategias. Además las riñas entre los líderes de la oposición (eje Castañeda y Andrade) hacían imposible hacer un frente común contra el régimen autoritario. Solidaridad Nacional y Somos Perú, anduvieron por su lado en la cuestión política.

Los partidos tradicionales o lo que quedaba de ellos, apenas tenían presencia en las provincias o en el mejor de los casos en ciertas zonas del país como fue el caso del Apra en su bastión conocido como el «sólido norte» que agrupaba a los departamentos de La Libertad y Lambayeque, teniéndolo bajo su control durante más de setenta años. Los nuevos partidos que lucharon contra la dictadura (ejm Perú Posible, Solidaridad Nacional y Somos Perú) no estaban identificados con una región en especial, con los cuales se podría construir lazos partidarios que pudiera sostenerlos permanentemente. Por ello se puede conocer la razón de su aparatosa derrota, su participación en los comicios quería demostrar el éxito de la Transición como un proceso institucional que consolidara la partidocracia recientemente recuperada o la ilusión de esta. El problema se acrecentaba con la llamada regionalización, en que los partidos nacionales no podían adaptarse con la rapidez debido a la falta de una estrategia de lograr cimentarse políticamente tras el fin del Fujimorismo. Esto abría a una competencia de movimientos regionales que avasalló como un huracán toda la estructura política tradicional.

Las oportunidades históricas perdidas, para que esta transición política pudiese reivindicarse ante la ciudadanía. Más que ello, esta parte de la historia es una muestra más de su incapacidad para lograr la reconstrucción institucional del Perú a partir de la caída de Fujimori. Por el contrario, es una transición en donde la política fue, aunque parezca lo contrario, un factor ausente. No hubo extremismo ideológico ni por lo tanto, ámbitos en los cuales podían formularse los acuerdos y alianzas bajo estos términos. Lo que tenían en común a la oposición era la posibilidad de «abrir» el sistema luego de una década en que se fue saturado por la figura de Fujimori.
Un error que el flamante régimen democrático cometió, no fue asegurar una importante base partidaria que pudiera ser su base legitimadora ante la ciudadanía dada su participación en las protestas contra Fujimori. Como esto tuvo una lógica de enfrentar el fraude electoral solamente y no construir un nuevo orden político que había salido tras las elecciones. Con partidos con marcado personalismo era sumamente difícil hacer una coalición política que no fuera más allá de ver fuera a Fujimori. Se bloqueó porque no fue reformista ni lograr desmantelar la idiosincrasia autoritaria de la sociedad peruana. El fracaso de Toledo no es solo es de su presidencia es el fracaso de la transición y una pronta nostalgia por el autoritarismo.

Estos factores, hicieron que la gente se desilusionara con el régimen democrático, apelando la figura de un salvador, caudillo u hombre fuerte que pudiera sortear la enorme crisis. Era una situación paradójica frente al resto de países de Latinoamérica. Mientras que en Argentina, Chile, Uruguay y Brasil finiquitaban sus gobiernos militares; el Perú se encaminaba de nuevo a un régimen dictatorial. Cuando se dio el autogolpe de 1992, la clase política desapareció del mapa. No tenía sentido para la población, seguir confiando en una democracia que era incapaz de resolver los problemas más apremiantes. El recuerdo de esa oportunidad perdida afloraba en esos momentos y aquel error no era perdonado. Cuando la democracia se restauró en 2000, la clase política no pudo volver con fuerza al escenario político como pasó en 1980, tras el fin del gobierno militar. Más que eso, hubo una seguidilla de errores que los partidos políticos (ej. Perú Posible y Frente Independiente Moralizador) siguieron cometieron. Siendo asociados con la corrupción y la ineficacia (ej. escándalos relacionados con el gobierno de Toledo).

La partidocracia empezó a actuar de forma negligente, como si el autoritarismo fujimontesinista no hubiese existido o fuera un mero accidente. Parecía que estaba cometiendo los mismos errores del segundo Belaundismo, al no poder ni intentar fortalecer la democracia recién recuperada. La gente estaba esperanzada que la vuelta a la democracia, pudiese resolver los problemas que dejaba el Docenio Militar, por ello depositaron su confianza en el retorno de Acción Popular en la política como había pasado en su primer gobierno. Cuando se dio el terrorismo, este decidió entregar el mando a los militares. Desentendiéndose del problema, lo cual fue un grave error que dio la 
sensación de abandono al pueblo al permitir que las fuerzas del orden cometiesen una serie de excesos.

A diferencias de otras elecciones, en que las cuestiones ideológicas marcaban una gran diferencia entre los postulantes para las campañas presidenciales (ej. Armando Villanueva del Campo y Fernando Belaunde en las elecciones de 1980) tuvieran diferencias palpables en torno al discurso y los mensajes dirigidos a determinados públicos cautivos. La clase media estaba agrupada en Acción Popular y el Partidos Popular Cristiano o los obreros en favor del Apra o Izquierda Unida. Pero la enorme similitud de discursos, generó confusión y desazón entre los votantes de comienzos del siglo. Debido a la falta de referencias ideológicas, enfatizando las personalidades que simbolizaban los candidatos. Toledo (El cholo triunfador), Lourdes Flores (la primera mujer en una candidatura presidencial) y Alan García (el líder carismático).

Los presidentes que ganaron las elecciones desde fines de 1980 se caracterizaron por surgir de la improvisación, de no estar respaldados por una partidocracia que pudiera respaldar sus políticas y no desgastarse rápidamente el apoyo que tenía entre la población. La crisis argentina demostró cuan vulnerable era el sistema democrático ante el desborde popular cuando la población veía que sus demandas no estaban cumpliéndose. La terrible consecuencia era el flagelo de la inestabilidad política que veía arrastrando desde los albores de la independencia. El mejor ejemplo de aquel desbordamiento que hacía que los mandatarios les fuera imposible poder manejar situaciones de estallido social o violencia política. Aquello era una seria advertencia para el Perú, lograse con su reciente ganada democracia, pudiera diferenciarse de los otros países que pasaban por dichas situaciones

Los partidos políticos, estaban vinculados totalmente en tener un líder máximo que era a la vez fundador y conductor. Al igual que el Fujimorismo, que no podía desprenderse de su líder y creador. La oposición política estaba ligada de forma excesiva a sus primeros líderes. No se había logrado crear una estructura partidaria de mandos medios y subalternos que pudiera conectar a la alta dirigencia del partido con las masas. Esto agrupa todas las funciones partidarias, sin querer compartir el poder o simplemente como socios menores de algún gobierno. Basándose en una frase que dijo el intelectual Luís Alberto Sánchez: «En el Apra hay solo un número uno, y muchos números seis». Está impregnado en la política peruana al comenzar el siglo XXI, dominada totalmente por una lógica personalista, desideologizada y no construir una serie de liderazgos que pudiera continuar con el desarrollo del partido o proyecto político. La investigación de Murokami da prioridad a este punto.

Los partidos políticos estaban sobredimensionados en su capacidad para lograr salir del marasmo que dejó la dictadura fujimorista. Las metas planteadas en el ideal de reconstrucción institucional republicana estaban enmarcados en un proceso sumamente complejo en el cual, no estaban preparados en lo más absoluto. Los niveles exigidos hacían que cada una de las tareas encomendadas fuera de difícil ejecución. En primer lugar el hecho de fortalecer a los partidos políticos era la más difícil de todas. Porque estos, no tenían la capacidad de endose ni desprenderse de la sombra de sus caudillos fundadores tampoco autonomía institucional.

Otro problema que había era quela descentralización, proyecto apoyado por el gobierno de Transición y continuado por la gestión de Toledo, estaba causando serios problemas para los partidos nacionales que eran tildados de ser capitalinos, centralistas y ser poco atractivos electoralmente para personas interesadas en hacer carrera en la política departamental; finalmente la imagen de los partidos no había cambiado ante los ojos de la Sociedad Civil, que se veía como protagonista del fin de la dictadura fujimorista que la partidocracia que actuó como testigo secundario. Mostrando que la transición no había logrado su objetivo. Esta consideraba que el sistema de partidos estaba vinculado al pasado, la corrupción y la ineficiencia.

A diferencia de otras marchas contra las dictaduras de Sánchez Cerro, Benavides, Odría y Morales Bermúdez, en que los jóvenes estaban obligados a seguir a rajatabla la disciplina que suponía estar en la militancia política (especialmente la de las agrupaciones de izquierda); esta nueva generación política consideraba que solamente el apoyo a la idea de la democracia por si sola podía regenerar el país y no una ideología partidaria en específico. La población aprobaba el activismo político de la nueva generación, ya que estos no se agrupaban en círculos políticos cerrados, ideologizados y clandestinos (ejm el Grupo Cahuide donde militó Mario Vargas Llosa en su juventud, en la lucha contra la tiranía odriista) más que todo, invitaban a una heterogénea coalición para apoyar su causa. Eso era el requisito más importante en esta nueva realidad. 
La juventud, a fines del siglo $\mathrm{XX}$, inauguraba una nueva dinámica política. La llamada política sin militancia, concepto que se ha manifestado como la identidad política de la juventud del tercer milenio. Es un dato importante, porque la juventud no se agrupa en partidos políticos determinados y se decanta por los colectivos. Pocos de los universitarios que participaron en la marcha de los Cuatro Suyos, militaban en partidos políticos organizados o lo que quedaba de ellos. Había una importante corriente que consideraba que la militancia política más que un importante requisito... era más un estorbo para lograr la adhesión de la ciudadanía. El sentimiento de rabia y frustración que había entre la juventud por todo lo que pasaba y como habían constituido asociaciones como Regeneración, Anti-Megafraude, Juventud Popular, Colectivo Todas las Artes en que habían puesto muchos esfuerzos en reflejar su opinión en contra de la reelección de Fujimori en los meses previos antes de las marcha de los Cuatro Suyos.

\section{Contexto económico}

En el campo económico, sus medidas hicieron que la crisis se agravase más. 20 años este esquema de errores se repetía, ya que en ese momento se estaba dando el hecho que la presidencia de Toledo peligraba por los pedidos de vacancia y el fracaso de la descentralización mostraba que estos no habían podido lograr colmar las expectativas de la gente que deseaba superar la corrupción del régimen fujimorista. Parecía lejano esos tiempos en que los partidos encabezaban la lucha contra la dictadura y la gente volvía depositar su confianza en estos.

La oposición política siempre tuvo propuestas en favor de no tocar el modelo económico, herencia del Fujimorismo. Por ello no articularon propuestas en torno a una mayor lucha contra la pobreza, superar las desigualdades como corregir ciertos aspectos del modelo neoliberal que perjudicaban a la población o quitarle el sesgo autoritario del neoliberalismo impuesto. La partidocracia que surgió tras la caída del Fujimorismo no mostró mayores proyecciones en el asunto de la lucha contra la miseria económica o tratando de relegarlos a los programas sociales de carácter asistencialista. No hubo un proyecto específico para tratar con dicho problema, más bien solo tuvo un enfoque general.
Los problemas políticos de la República, se han manifestado cuando terminó esta etapa histórica al lograr normalizar las elecciones, evitar que se desatase un golpe de Estado y lograr restaurar la democracia. Manifestó sus terribles limitaciones al no tener un proyecto constitucional que pudiera sostenerlo por mucho tiempo. Lo cual mostró que sus objetivos eran a corto plazo, mostrando que no pudieron sostener vínculos con los ciudadanos después de las movilizaciones. La aspiración por lograr una democracia funcional, solo se quedó en la cuestión electoral para garantizar que no haya fraudes e irregularidades en los comicios. Por lo visto, eso sería uno de los puntos débiles que dejó la restauración de la democracia en que dejo muchos vacíos en diferentes cuestiones institucionales que llegaron poco tiempo después. Además como parte de las movilizaciones políticas no tenían vínculos con organizaciones partidarias disciplinadas e importantes no pudieron funcionando después de su cometido y ser punto de referencia. Menos aún espacios en provincias, que pudieran lograr asidero fuera de Lima.

Desde 1990, se ha desarrollado un modelo político que se ha fundamentado en los medios de comunicación masiva como la televisión y no en la construcción de una organización partidaria que englobe a los sectores sociales. Por ello vemos uno de los problemas más complejos que ha tenido nuestra historia republicana; al carecer o tener instituciones sólidas que tutelen el desarrollo de nuestro país. Las agrupaciones políticas no han podido cimentarse en este nuevo periodo y adolecen de legitimidad por parte de las masas ciudadanas y pone el ejemplo de que estos no pudieron recolectar el número de firmas para seguir vigentes en el escenario electoral y estar conducido por proyectos personales. La preocupación de la transición política porque debía estar marcada por una reinstitucionalización de la democracia para evitar los errores del pasado, lamentablemente su visión a lo largo de los años transcurridos no pudo cumplirse.

Las elecciones que siguieron a la caída de Fujimori, hicieron que la oposición política no tratara de mostrar cambios ni hacer el mínimo esfuerzo por razones propagandísticas. Más que todo hubo una mayor asimilación en los discursos, estilos políticos y apoyo al modelo económico entre los candidatos que disputaban la presidencia, tras la partida del candidato presidente. Eso demuestra un proyecto a largo plazo, que siguiera a la caída de la dictadura. Por ello la transición pos fujimorista no logró generar una imagen 
de renovación entre a la ciudadanía que la alejaba de las prácticas corruptas y clientelistas del pasado. La partidocracia no pudo consolidarse tras la caída del Fujimorismo. Los principales candidatos Lourdes Flores, Alejandro Toledo y Alan García estaban englobados en un sistema político cerrado y caudillista que impedía cualquier tipo de renovación. Perú Posible fue el grupo que caracteriza en la lógica movimientista. Jamás evolucionó a un partido de masas y de raigambre popular.

Esta nueva época, los agentes económicos tenían mayor peso que los operadores políticos que han quedo atrás. Asimismo los medios de comunicación empezaron a remplazar cada vez más a los partidos políticos como referencia de la población a la hora de hacer política por la enorme influencia que estos podían ejercer a los ciudadanos. A medida que avanzaba la tecnología, la influencia mediática se acrecentaba, mientras que la partidocracia quedaba relegada en un plano secundario y relegado a una cuestión protocolaria. Asimismo cabe destacar que la época de lucha contra el Fujimorismo, se basó en una lucha entre dos variantes peruanas del neoliberalismo que uno apelaba al libre mercado y otro que abogaba por el autoritarismo caudillista. Por lo que se puede observar que no está marcado por un enfrentamiento ideológico partidario. El electorado se inclina por apoyar un capitalismo con más libertades; antes que un capitalismo con menos libertades o que un poder ejecutivo excesivamente concentrado en una sola persona o grupo en particular. No se votó por un cambio ideológico, sino por la idea de la alternancia en el gobierno que permite un mayor control del ciudadano del poder. Eso era el punto primordial que se vino expresado en los debates públicos y en las calles.

El contexto socio-económico de este nuevo siglo no está marcado en un esquema cerrado de blanco y negro en términos políticos. En que buena parte de la historia republicana del Perú, estuvo marcado por la lucha entre la minoría dueña de los recursos que gobierna el país, a través de un sistema político cerrado o por los militarismo, contra una mayoría de pobres que carecían de ciudadanía y expectativas por el futuro. Por ello prosperarían las opciones políticas radicales que llevarían a una etapa marcada por los conflictos. Pero con el advenimiento de la clase media en la política, los radicalismos ocuparon un rol secundario. Asimismo el péndulo de gobiernos civiles y militares, también estaba quedándose relegado por la ola de democratización que acompańaban el fin de las ideologías radicales y el ascenso del neoliberalismo a finales del siglo XX. La mejora de la economía impulsó la estabilidad política y aminoró los conflictos sociales al cambiar las aspiraciones de una población de lograr la prosperidad, siendo parte de esta.

El error principal del nuevo régimen democrático instalado en el poder; fue enfatizar en grado excesivo en la economía. La institucionalidad quedó de lado, ante el crecimiento de la economía y dar la sensación de bonanza. Era más cómodo para el nuevo presidente, abocarse al desarrollo económico que lograr un complejo proyecto político institucional de largo plazo. A pesar de que se había nombrado en los puestos claves bajo la premisa de la tecnocracia liberal...el empresariado mostraba mucha desconfianza, dado que el régimen democrático no podía hacer frente a los problemas que se cernían con la nación como la violencia al interior del país, las continuas huelgas y el descrédito del gobierno. Acostumbrado a la tranquilidad que brindaba el régimen fujimorista, especialmente desde 1992, veía con cierto estupor que apenas caía un régimen autoritario; luego de la euforia inicial los problemas de gobernabilidad entraban de lleno.

\section{Los problemas de adaptación}

El viejo esquema político continuó indemne, a pesar de la caída de la dictadura y la persecución de los males que esta había generado al país. Podemos observar que la oposición política nunca tuvo un cuerpo profesional de líderes y dirigentes que pudieran lograr articular un proyecto nacional. Más que todo, está marcado en la opción de lograr ganar las elecciones en medio de una amalgama de propuestas improvisadas. Por ello, se habla que las organizaciones no tuvieron la voluntad de cambiar dicho esquema. Debido que el retorno de la democracia no se ha vinculado con la organización ni la con construcción de liderazgos o propuestas referentes a la institucionalidad democrática. Es decir los partidos están compuestos por individuos que aspiran ser burócratas y no enfatizar el rol articulador y cohesionador de la política.

Las metas planteadas en el ideal de reconstrucción institucional republicana estaban enmarcados en un proceso sumamente complejo en el cual, no estaban preparados en lo más absoluto. Los niveles exigidos hacían que cada una de las tareas encomendadas 
fuera de difícil ejecución. En primer lugar el hecho de fortalecer a los partidos políticos era la más difícil de todas. Porque estos, no tenían la capacidad de endose ni desprenderse de la sombra de sus caudillos fundadores tampoco autonomía institucional.

Una de las agrupaciones políticas específicas que no pudo volver con fuerza a la arena política fue la izquierda. A diferencia del APRA, que logró revertir su desaparición del espectro político gracias al regreso del exilio de Alan García. Esta tuvo un papel secundario en la lucha por la democracia, que se dio en el 2000. Ya que los noventa, fue una década en que los partidos de índole izquierdista dejaron de ser referentes políticos debido a la nueva realidad imperante a finales del siglo XX. Cuando la pequeña clase obrera desapareció y dejó paso al trabajador informal. Este nuevo público se decantaba por el populismo neoliberal que por la lucha de clase. Además está muy perjudicada por la desaparición de los sindicatos que le daban un importante peso a la Izquierda a la hora de plantear demandas. Asimismo las elecciones en que participaron $(1995,2000$ y 2001) fueron un fracaso rotundo que apenas logró un magro porcentaje. Lo único que pudieron hacer fue aliarse con el Peruposibilismo para lograr poner a sus militantes en el congreso.

Este panorama desolador, hacen que se vean obligados a participar como socios menores de la gran coalición de partidos, colectivos y movimientos que se movilizaron en contra de Fujimori. Ante esta situación, los líderes izquierdistas dejaron de enfocarse mucho en la acción política ni en debates ideológicos y se centraron en participar en las ONG (Organizaciones No Gubernamentales) en que estaba vinculado el mundo académico. La Izquierda logró cierto predominio intelectual y manteniendo vigencia, dado que algunos de sus miembros más notables estuvieron en el gobierno de Paniagua como Gustavo Adrianzén como asesor del presidente y Diego García Sayán que fungió como ministro de Justicia. Logrando su mayor éxito en conformar la Comisión de la Verdad y Reconciliación para investigar la violencia terrorista. Para muchas personas, consideraron que era la incapacidad de esta de poder volver a ser la fuerza política de antaño.

La ciudadanía había apoyado y celebrado la caída de Fujimori...no estaba dispuesta a cambiar la Carta Magna de 1993. Lo cual se generó una dicotomía entre los partidos de la oposición y el pueblo. Buscar un amplio consenso entre diversos sectores complicaba el asunto ya que muchos sectores de la sociedad civil tenían dudas si un cambio podría más bien perjudicar al país, debido que el documento jurídico había logrado cimentar la tan deseada estabilidad macroeconómica. Además la caída del dictador se dio en el marco de respeto a la legalidad, los colaboradores del fenecido líder autoritario eran llevados ante la justicia y el fin de un régimen de tamaña naturaleza no se dio por el clásico cuartelazo como ocurría en la época de los caudillos en el siglo XIX.

Los detractores de la reelección de Fujimori que rechazaban a los partidos políticos, a pesar de que las agrupaciones políticas compartían sus deseos y anhelos de ver fuera al régimen fujimorista. Esto demuestra la total desconexión entre los ciudadanos furiosos que defendían sus derechos robados y los partidos que estaban golpeados y debilitados tras un decenio fujimorista. No se formularon una serie de propuestas para mejorar el desempeńo de los grupos políticos en el futuro cercano. Los colectivos prodemocracia; aparte de su nulo interés en evolucionar en un movimiento partidario de alcance nacional no formularon ideas para que los partidos pudieran recuperarse institucionalmente. Mostrando como pasó con el Fujimorismo, la pobreza programática de su proyecto político.

La lucha intensa por vencer al autoritarismo fujimorista, no desterró el estigma de que la democracia estaba asociada a la ineficiencia, el desgobierno, la falta de principio de autoridad y debilidad crónica que aquejaba al país cuando los partidos tradicionales han renovado el país. Es decir que el pueblo peruano no se reconciliado con la vieja partidocracia, mostrando que ambos solo los une la hostilidad hacia el régimen fujimomontesinista. Todo está relacionado, cuando la democracia regresó en 1980 al terminar 12 ańos de dictadura militar. Esto generó grandes expectativas por parte de la ciudadanía, ya que participaban importantes agrupaciones de marcada ideología ya se de izquierda o derecha. Poco después de este auspicioso, empezaron los problemas de gran envergadura como la aparición de la insurgencia terrorista de Sendero Luminoso y el MRTA, la galopante crisis económica, anarquía imperante, crisis social, aumento de la pobreza y contrainsurgencia brutal por parte de las Fuerzas del orden.

La transición conservó el Presidencialismo, que englobaba parte del esquema de gobierno fujimorista. Por ello era difícil que se pudiera asentar una nueva 
reconstrucción del poder de los partidos. Ya que este sistema, hace que el presidente concentra el poder y parte de las decisiones están en manos del ejecutivo. Lo cual hace que el poder del congreso se quede muy debilitado y no puede lograr que los partidos políticos representados puedan tener cierto margen de maniobra. Ante ello, los partidos pierden su poder de decisión al quedar arrinconados por el poder presidencial. Dando la sensación de que el congreso se había vuelto un ente decorativo y el único que podía cambiar las cosas en el país era el presidente. La oposición política no se formuló de forma permanente, la posibilidad de hacer cambios de modelo presidencialista. Por ello los sucesores de Fujimori no tuvieron interés en cambiar el esquema político, sino que decidieron reforzar el sistema.

El error reiterativo de la Transición política ha sido generalmente caracterizo por siempre quedar como un proceso a medias y no ser llevado de forma radical que pudiera de una vez por todas terminar con la lacra de la corrupción política. Para evitar que sucediera un escenario parecido en el futuro. Sin alguna base política ni partidaria, era bastante difícil que un proyecto político tuviera una completa evolución. Asimismo el esquema personalista de hacer política se mantuvo vigente. Es decir no hay una ruptura de forma total entre el estilo fujimorista de hacer política con el pasado y el presente. La transición solo hizo volver al escenario político a los partidos en lo formal, pero no fue un cambio real que iba a cambiar la historia.

La oposición política no articuló planes para implementar verdaderas alternativas con respecto a materia política, económica y social. Solo estaban concentrados en ganar las elecciones y mantener a ciertas estructuras socioeconómicas que surgió al implementarse el neoliberalismo en el Perú. La oposición política no ambicionaba una transformación institucional y querer hacer ciertas mejores en diversas facetas que involucraban a las demandas de la población. En su mayoría, solo aspiraban a hacer el Fujimorismo sin Fujimori, solo enfocado en el aspecto económico que apenas mostraban discrepancias. El más enfático de estos fue Alejandro Toledo que lo dejó plasmado en su gobierno. Asimismo no cuestionan el modelo económico y consideran mantener el esquema tecnocrático.

Una transición política, que pudiera consolidar un modelo democrático que pudiera mantener vigencia el mayor tiempo posible se veía con serias dificultades.
Vemos una mayor precariedad y fragilidad de la democracia. Podemos destacar, que a diferencia de otras transiciones democráticas que presentaban fallas y que los regímenes democráticos eran barridos del mapa por un líder mesiánico o una coyuntura complicada. Como debemos destacar, en los ochenta ante los errores de la clase política al no poder solucionar el problema del terrorismo y la terrible crisis económica. Por ello el desencanto fue tal, que la asunción de Fujimori borró de forma abrupta el panorama político. Debemos mencionar porque la transición política de 2000 no derivó hacia un viraje autoritario, se debió a las nuevas circunstancias que se vivía en esa primera década.

Las agrupaciones les interesaba maximizar oportunidades electorales, en vez de estar en un partido nacional que generaría muchos costos para un objetivo de corto plazo que era ganar las elecciones. Muestra en su investigación de que el movimiento no tenía una estructura nacional ni capacidad de negociación política y termina siendo conducido por un «independiente» como Toledo, en que su única manera de mostrar su valía era la conformación de un equipo de tecnócratas en su plancha electoral y eso se manifestó en las elecciones de 2001 para legitimar su candidatura un par de meses después. Asimismo habla de una democratización frustrada que no pudo conseguir su objetivo de lograr afianzar un verdadero régimen institucional. Por otra parte, la política marcada por el personalismo, sin vínculos institucionales con los partidos, convirtiéndolos en un tipo de franquicia y enfocándose en el márquetin electoral mas no en una propuesta política.

El desencanto a los partidos políticos llego demasiado pronto. Notándose en las elecciones regionales que se celebraron en octubre de 2002, en que fueron desplazados por los regionales...salvo el Apra que tuvo ciertas regiones en su control como el departamento de La Libertad. Se demostró que no estaban preparados para la enorme tarea que se presentaba. Se notaba que no tenían el suficiente alcance nacional para poder competir ni arraigo popular entre las masas provincianas como pasó en los ańos treinta y secundaron a gran parte de sus propuestas y líderes. Además solo tenían presencia en el congreso y ejecutivo, lo cual daba una falsa impresión de que estas agrupaciones tenían fuerza.

Perú Posible, fue la organización que había luchado para recuperar la democracia, ahora se hacía añicos al entrar en el gobierno. Lo cual hizo que se dudaba de su 
calidad como organización democrática, ya que seguía el mismo patrón de los partidos políticos que llegaban al poder. Eran organizaciones que estaban poco interesadas en continuar un proyecto institucional, más que todo veía al Estado como parte de un botín para utilizarlo para prebendas, poner a gente poco cualificada en puestos de confianza y hacer que la cuestión partidaria se volviera un asunto particular, como el caso del favorecimiento de los familiares de los militantes en diversas cuestiones económicas.

Los casos de corrupción que involucraban a dirigentes y militantes de Perú Posible, le quitó popularidad y apoyo de los ciudadanos. Parecía que el retorno del autoritarismo estaba a la vuelta de la esquina. Este cúmulo de males decisiones, debilitaban enormemente al oficialismo. Toda esta acumulación de errores, solo era muestra de una situación que afectaba a todos los partidos gobernantes del Hemisferio Occidental, haciendo la gobernabilidad democrática bastante precaria que daba paso a improvisados y caudillos pintorescos como pasó con la desaparición del sistema partidario tradicional venezolano a favor del Chavismo por no lograr hallar soluciones a problemas que aquejaban a la población o el caso del fracaso que significó para la Unión Cívica Radical la salida abrupta del presidente de la Rúa por su mal manejo de la economía. Todos estos fracasos de gestión debilitaban el sistema de partidos hasta hacerlo sumamente precario. Una muestra de que la ciudadanía ya no toleraría la incompetencia de sus clases dirigentes, lo cual hacía que su derecho al voto tuviera un aire de venganza y castigo. Por lo cual, la gente castigaba duramente en las elecciones al sistema de partidos que no fallaban terriblemente en asuntos de gestión gubernamental. Más que todo la partidocracia se volvió un examen de desempeño gubernamental.

A diferencia de los problema que tuvo que enfrentar el segundo Belaundismo y el primer gobierno aprista con problemas que ponían en peligro la viabilidad del Perú. El gobierno toledista no tuvo que enfrentar un escenario de tamaña envergadura. El crecimiento económico hizo que parte de la población no tuviera ánimos para un cambio brutal de régimen. Además en esos años, se daban casos de inestabilidad política en Ecuador y Bolivia, cuando los presidentes de corte neoliberal Lucio Gutiérrez y Gonzalo Sánchez de Losada tuvieron que renunciar ante la presión popular. Dicho escenario contagioso, fue tomado en consideración para evitar que esto se diese en Perú.
Que trata de contextualizar este periodo nuevo de nuestra historia y menciona que este periodo estuvo inmerso en el neoliberalismo. Podemos afirmar que se llega a la segunda fase histórica de esta corriente económica. Citando a Adrianzén en que considera que esto no pudo haber concluido en las elecciones que se celebraron después de la caída del Fujimorismo y considera que los cambios profundos debieron haber marcado el derrotero de este periodo histórico. Mantener la estructura neoliberal ha sido el mayor obstáculo para que esta nueva etapa política se pudiera consolidar institucionalmente y hacer que la democracia peruana pudiera fortalecerse y legitimarse.

El régimen democrático restaurado formalizó o hizo en el mejor de los casos hizo el intento para que la política partidaria pudiera institucionalizarse. Con la promulgación de la Ley de Partidos Políticos en noviembre de 2003. El objetivo de esta norma, uno de los pocos proyectos institucionales del régimen democrático, fue evitar un escenario similar con la década fujimorista con un ordenamiento de los partidos que participaban en la vida política. Pero esta norma legal no logró evitar que los partidos tradicionales se siguieran debilitando. Era una muestra de que las intenciones democráticas no podían plasmarse en la realidad. Ya que los comicios electorales mostraban que partidos de reciente creación ganaban las elecciones y liderados por figuras carismáticas con amplio margen de ganancias. Mientras más veterana era una agrupación política; más se debilitaba como organización que pudiera ser relevante en el juego democrático. Solo un líder carismático podía salvar algunas agrupaciones políticas (ejm El Apra) de la debacle.

El objetivo de lograr tener un mejor sistema partidario que dicha ley contemplaba se estrellaba contra la realidad. El principal error que tuvo la norma fue no tener un mecanismo de sanción en caso que no fuera acatada, dado el nivel de informalidad de las agrupaciones políticas heredado tras el Fujimorismo; esta ley no sería obedecida por todas por simple conveniencia política dado los inconvenientes que presentaba, ya que se descubrirían las falencias de su partido y tomaría mucho tiempo en lograr institucionalizarlo. Además los nuevos partidos «independientes» mostraban mucho más flexibilidad que los partidos tradicionales.

El punto más importante de su reflexión es que la recuperación democrática en el Perú era un proceso lento y de marcada fragilidad, dado el amplio historial 
de transiciones políticas truncas como había pasado con los procesos de 1963 y 1978, en este último proceso político, participó en la Asamblea Constituyente. Por ello, la llegada del nuevo presidente no debía distraer en un medio de una euforia triunfalista por los principales problemas que aquejan al país. Más que ello era el momento propicio para la refundación constitucional de la nación, borrar la herencia fujimorista. La recién recuperada democracia era mucho más frágil de lo uno imaginaba. Pasando de una época caótica, con el autoritarismo fujimorista, a otra época caótica con el retorno democrático institucional. Ambos bandos era responsables de la crisis que se había cernido en aquella región. El gobierno por apostar a ultranza con el programa neoliberal al querer reanudar las privatizaciones y sin consultar con los arequipeños; en segundo lugar las protestas lideradas por el alcalde Juan Manuel Guillén habían degenerado en intolerancia, violencia, un escenario apocalíptico, con fallecidos y heridos, un gobierno debilitado, ministros renunciantes y ahuyentar el turismo, motor importante de la economía nacional.

\section{La preponderancia de la tecnocracia sobre la partidocracia}

La tecnocracia, sería la base del gobierno democrático al igual que la dictadura fujimorista. Convirtiéndose en un poder que gobernaba en la práctica, ya que la partidocracia ya no era una opción de gobierno. Por lo cual, el enfoque tecnocrático prevaleció tras la caída de la dictadura. Por ello la debilidad de los partidos se ha crecentado con el transcurrir de los ańos, especialmente tras la caída de la dictadura; acrecentándose de este poder real. La política cada vez es más desplazado por el mercado y cada vez tiene un carácter protocolario. Los agentes económicos han decidido cada vez más la marcha del país, una vez terminado los tumultos políticos. Aquello solo fue un contratiempo, ante el esquema tecnocrático.

El espacio público cada vez más reducido de la partidocracia es una muestra de que una característica del siglo XX ha quedado para la historia y el nuevo siglo estará dominado por la economía neoliberal. La carencia de una verdadera organización política fue el factor preponderante para continuar con la legitimidad de la institucionalidad democrática y apoyarse el gobierno en actores no democráticos (tecnócratas).
Fue en ese momento, en que de manera silenciosa empiezan a surgir los movimientos regionales que desplazó a los partidos nacionales en el interior del país en los comicios venideros. Mostrando un problema que la transición no supo prever y mostró su carácter capitalino y que le dio la espalda a las provincias o no tenía legitimidad de estas. El sentimiento de amarga decepción tras esa etapa de reestructuración institucional contra los partidos políticos. Pero cabe destacar que la falta de una organización política que pudiera romper encasillamiento de estar solamente en las protestas contra la dictadura y no poder convertirse en intermediarias entre la ciudadanía y el gobierno.

Las preocupaciones que tiene esta, es mejorar la calidad del régimen democrático, enfocado en lo institucional y que el poder no tuviera mandatarios que buscaran prolongar sus mandatos. Según esta visión, la economía de mercado ha logrado cierta firmeza en el rumbo de la nación y para sostenerlo el sistema debía mantener la formalidad democrática. Podía enfocarse en la premisa: "Sin democracia no hay mercado o sin mercado no hay democracia». La ciudadanía tiene demandas más específicas en torno a diversas temáticas como la situación económica. Además el afán de un presidente de prolongar su régimen, distraía del verdadero eje de desarrollo que era la economía, lo cual viabilizaba a las naciones.

El quinquenio que estuvo englobado en medio del fin del siglo XX y el comienzo del siglo XXI, estuvo signado por el fin del Fujimorismo, el gobierno provisional de Valentín Paniagua, la asunción de Toledo como presidente y los problemas que este tuvo que enfrentar en sus primeros tiempos. Todos estos estos que menciona el autor Álvaro Vargas Llosa que habla en el conjunto de ensayos: "Últimas noticias del nuevo idiota iberoamericano» comenta sobre la historia reciente del Perú. Todo esto, generó resquemores en nuestra economía que veía como peligraba ante la inestabilidad política suscitada. Los dos primeros años del gobierno toledista fue una prolongación de la crisis que vivía el país. Especialmente con el espinoso asunto del Arequipazo que minó su popularidad, mostrando la debilidad que tenía un régimen que surgió con la transición democrática. Por ello, se puede considerar que la legitimación del modelo neoliberal podía mantener un nivel de gobernabilidad, dándole una institucionalidad democrática. Lo preocupante de aquellos tiempos era salvaguardar el modelo económico de los avatares de una nación como Perú. 


\section{Referencias bibliográficas}

Adrianzén, Alberto (2009). Partidos, sistemas politicos y elecciones regionales. Arequipa: Universidad Nacional de San Agustín.

Ames, Rolando (2001) Situación de la democracia en el Perú (2000-2001). Lima: Fondo editorial PUCP.

Cavero, Jans (2008). La democracia incompleta: Una retrospectiva a la gobernabilidad de Perú después de la transición democrática. Fundación CIDOB.

Crabtree, John (2006). Construir instituciones: democracia, desarrollo y desigualdad en el Perú desde 1980. Lima: Fondo Editorial de la PUCP.

DARgENT, Eduardo (2000). La transición interminable ¿qué pasó con los partidos politicos en el Perú? Lima: Comisión Andina de Juristas.

Dargent, Eduardo (2011). Demócratas precarios: elites y debilidad democrática en el Perú y América Latina. Lima: IEP.
Gervasoni, Carlos (2004, 22 de julio). ¿Hay una crisis de los partidos latinoamericanos? Centro para la Apertura y el Desarrollo de América Latina, $N^{\circ} 18$.

Grompone, Romeo (2005). La escisión inevitable-partidos y movimientos en el Perú actual. Lima: IEP.

LA RepúblicA (2001, 30 de mayo). La reforma constitucional, 7090.

Lauer, Mirko (2001, 07 de abril). Buscando al candidato ideal, La República, 7037

Mohme Seminario, Gustavo (2000, 18 de setiembre). La república y el nuevo Perú. La República, 6836.

Murokami, Yusuke (2007). El Perú en la Era del Chino-La politica no institucionalizada y el pueblo en busca de un salvador. Lima: IEP.

TAnaka, Martín (2004). Situación y perspectivas de los partidos políticos en la Región Andina: El caso peruano. Ágora democrática. Institute for Democracy and Electoral Assistance. 